\title{
Comparison of Zotarolimus-Eluting and Everolimus-Eluting Coronary Stents
}

\author{
Patrick W. Serruys, M.D., Ph.D., Sigmund Silber, M.D., Ph.D., \\ Scot Garg, M.B., Ch.B., M.R.C.P., Robert Jan van Geuns, M.D., Ph.D., \\ Gert Richardt, M.D., Pawel E. Buszman, M.D., Ph.D., Henning Kelbæk, M.D., \\ Adrianus Johannes van Boven, M.D., Ph.D., Sjoerd H. Hofma, M.D., Ph.D., \\ Axel Linke, M.D., Ph.D., Volker Klauss, M.D., Ph.D., William Wijns, M.D., Ph.D., \\ Carlos Macaya, M.D., Ph.D., Philippe Garot, M.D., Carlo DiMario, M.D., Ph.D., \\ Ganesh Manoharan, M.B., B.Ch., M.D., F.R.C.P., Ran Kornowski, M.D., \\ Thomas Ischinger, M.D., Ph.D., Antonio Bartorelli, M.D., Jacintha Ronden, Ph.D., \\ Marco Bressers, M.Sc., Pierre Gobbens, B.Sc., Manuela Negoita, M.D., \\ Frank van Leeuwen, M.D., and Stephan Windecker, M.D.
}

From Erasmus Medical Center (P.W.S. S.G., R.J.G.) and Cardialysis (J.R., M.B., P. Gobbens) - both in Rotterdam; and Medisch Centrum Leeuwarden, Leeuwarden (A.J.B., S.H.H.) - all in the Netherlands; Kardiologische Praxis und Praxisklinik (S.S.), University Hospital Munich (Innenstadt) (V.K.) and Hospital Bogenhausen (T.I.) - all in Munich; Herz-KreislaufZentrum, Segeberger Kliniken, Bad Segeberg (G.R.); and Herzzentrum Leipzig, Leipzig (A.L.) - all in Germany; Medical University of Silesia, Katowice, Poland (P.E.B.); Rigshospitalet, Copenhagen (H.K.); Onze Lieve Vrouw Ziekenhuis, Aalst, Belgium (W.W.); Hospital Universitario, Madrid (C.M.); Institut Cardiovasculaire Paris-Sud, Quincy, France (P. Garot); Royal Brompton Hospital, London (C.D.); Royal Victoria Hospital, Belfast, United Kingdom (G.M.); Rabin Medical Center, Tel Aviv University, Tel Aviv (R.K.); Centro Cardiologico Monzino, MiIan (A.B.); Medtronic, Santa Rosa, CA (M.N., F.L.); and Bern University Hospital, Bern, Switzerland (S.W.). Address reprint requests to Dr. Serruys at the Department of Cardiology, Erasmus Medical Center, Molewaterplein 40, Ba-583, 3015 GD Rotterdam, the Netherlands, or at p.w.j.c.serruys@erasmusmc.nl.

This article (10.1056/NEJMoa1004130) was published on June 16, 2010, at NEJM.org.

N EnglJ Med 2010;363:136-46.

Copyright (c) 2010 Massachusetts Medical Society.
ABSTRACT

\section{BACKGROUND}

New-generation coronary stents that release zotarolimus or everolimus have been shown to reduce the risk of restenosis. However, it is unclear whether there are differences in efficacy and safety between the two types of stents on the basis of prospectively adjudicated end points endorsed by the Food and Drug Administration.

METHODS

In this multicenter, noninferiority trial with minimal exclusion criteria, we randomly assigned 2292 patients to undergo treatment with coronary stents releasing either zotarolimus or everolimus. Twenty percent of patients were randomly selected for repeat angiography at 13 months. The primary end point was target-lesion failure, defined as a composite of death from cardiac causes, any myocardial infarction (not clearly attributable to a nontarget vessel), or clinically indicated targetlesion revascularization within 12 months. The secondary angiographic end point was the extent of in-stent stenosis at 13 months.

RESULTS

At least one off-label criterion for stent placement was present in $66 \%$ of patients. The zotarolimus-eluting stent was noninferior to the everolimus-eluting stent with respect to the primary end point, which occurred in $8.2 \%$ and $8.3 \%$ of patients, respectively ( $\mathrm{P}<0.001$ for noninferiority). There were no significant between-group differences in the rate of death from cardiac causes, any myocardial infarction, or revascularization. The rate of stent thrombosis was $2.3 \%$ in the zotarolimus-stent group and $1.5 \%$ in the everolimus-stent group ( $\mathrm{P}=0.17$ ). The zotarolimus-eluting stent was also noninferior regarding the degree $( \pm \mathrm{SD})$ of in-stent stenosis $(21.65 \pm 14.42 \%$ for zotarolimus vs. $19.76 \pm 14.64 \%$ for everolimus, $\mathrm{P}=0.04$ for noninferiority). In-stent late lumen loss was $0.27 \pm 0.43 \mathrm{~mm}$ in the zotarolimus-stent group versus $0.19 \pm 0.40 \mathrm{~mm}$ in the everolimusstent group $(\mathrm{P}=0.08)$. There were no significant between-group differences in the rate of adverse events.

\section{CONCLUSIONS}

At 13 months, the new-generation zotarolimus-eluting stent was found to be noninferior to the everolimus-eluting stent in a population of patients who had minimal exclusion criteria. (ClinicalTrials.gov number, NCT00617084.) 
T HE USE OF EARLY DRUG-ELUTING STENTS consisting of a metal platform and the controlled release of a therapeutic agent from a durable polymer matrix has partially addressed the problem of restenosis. ${ }^{1,2}$ Although these firstgeneration polymers were considered biocompatible, they have been associated with allergic reactions and inflammation, which in combination with incomplete strut endothelialization have led to early and late stent thrombosis. ${ }^{3}$

New-generation polymer coatings aim more specifically at mimicking the endothelial lining in order to prevent thrombotic complications. In addition, basic research has shown that some of these polymeric materials could potentially upregulate genes related to thrombosis, inflammation, and vasoconstriction. ${ }^{4}$ The polymer used with the Resolute zotarolimus-eluting stent (Medtronic CardioVascular) is a mixture of a hydrophilic biocompatible component that faces the endoluminal surface and a hydrophobic component that is attached to the metal stent surface and serves as a drug reservoir, enabling sustained release of zotarolimus to control neointimal hyperplasia in patients with complex conditions and subgroups of lesions, as shown by encouraging early results..$^{5-9}$

The purpose of this study, called the Resolute All Comers trial, was to compare the Resolute zotarolimus-eluting stent with an everolimuseluting stent (Xience V, Abbott Vascular Devices) in an unrestricted, multicenter, open-label, randomized, controlled, noninferiority trial in patients undergoing percutaneous coronary intervention (PCI) in everyday clinical practice.

\section{METHODS}

\section{PATIENTS}

From April 30, 2008, to October 28, 2008, we recruited 2292 adult patients with chronic, stable coronary artery disease or acute coronary syndromes, including myocardial infarction with or without ST-segment elevation. Patients were eligible if they had at least one coronary lesion with stenosis of more than $50 \%$ in a vessel with a reference diameter of 2.25 to $4.0 \mathrm{~mm}$. No restriction was placed on the total number of treated lesions, treated vessels, lesion length, or number of stents implanted. The exclusion criteria were a known intolerance to a study drug, metal alloys, or contrast media; planned surgery within 6 months after the index procedure; childbearing potential; and participation in another trial before reaching the primary end point.

At least one off-label criterion was present in 1520 patients $(66.3 \%)$. Off-label use included the placement of a stent in patients with at least one of the following clinical or lesion characteristics: renal insufficiency (creatinine level, $\geq 140 \mu \mathrm{mol}$ per liter [1.6 mg per deciliter]), an ejection fraction of less than $30 \%$, the occurrence of acute myocardial infarction within the previous 72 hours, more than one lesion per vessel, at least two vessels with stents, a lesion measuring more than $27 \mathrm{~mm}$, bifurcations, bypass grafts, in-stent restenosis, unprotected left main artery (without a functioning bypass graft), lesions with thrombus, or total occlusion.

The study complied with the provisions of the Declaration of Helsinki, and the study protocol was approved by the institutional review board at each study center. All patients provided written informed consent.

\section{STUDY DESIGN}

Patients were randomly assigned to undergo PCI with a coronary stent releasing either zotarolimus or everolimus. A subgroup of patients $(20 \%)$ was randomly assigned to undergo angiographic follow-up at 13 months. The study-group assignments were unknown to members of the independent clinical events committee, steering committee, data-management committee, Academic Research Organization (Cardialysis), and the sponsor (Medtronic CardioVascular). The principal investigator and the coprincipal investigators designed the study, in collaboration with the sponsor. The verification of data collection was performed by an independent monitoring organization (Premier Research Group). The independent group of statisticians at Academic Research Organization performed the analyses. Members of the steering committee wrote the first draft of the manuscript and vouch for the completeness and accuracy of the data gathering and analysis. The study was conducted in accordance with the trial protocol.

\section{STUDY PROCEDURES}

The zotarolimus-eluting stent was available in diameters of $2.25,2.50,2.75,3.00,3.50$, and $4.00 \mathrm{~mm}$ and in lengths of $8 \mathrm{~mm}$ and $14 \mathrm{~mm}$ for stents with a diameter of $2.75 \mathrm{~mm}$ or less, $9 \mathrm{~mm}$ and $15 \mathrm{~mm}$ for stents with a diameter of $3.00 \mathrm{~mm}$ or more, and 12, 14, 18, 24, and $30 \mathrm{~mm}$ for all 
available stent diameters. The everolimus-eluting stent was available in diameters of 2.25, 2.50, $2.75,3.00,3.50$, and $4.00 \mathrm{~mm}$, with each available in lengths of $8,12,15,18,23$, and $28 \mathrm{~mm}$.

Balloon angioplasty and stent implantation were performed according to standard techniques; direct stenting (without previous balloon dilatation) was allowed. The aim was to obtain full lesion coverage with one or multiple stents. No mixture of type of stents was permitted for a given patient unless the operator was unable to insert the study stent, in which case crossover to another nonstudy device of the operator's choice was possible. The aim was to treat all coronary lesions in one session; however, staged procedures (defined as procedures planned at the time of the index procedure and performed within 6 weeks with the same type of study stent) were permitted. In the case of unplanned revascularization procedures requiring stent implantation, it was recommended that physicians use the same type of study stent.

Procedural anticoagulation was achieved with unfractionated heparin at a dose of 5000 IU or 70 to $100 \mathrm{IU}$ per kilogram of body weight to maintain an activated clotting time of more than 250 seconds; the use of glycoprotein IIb/IIIa inhibitors was left to the operator's discretion. All patients who were enrolled in the study received at least $75 \mathrm{mg}$ of acetylsalicylic acid before the procedure. A loading dose of 300 to $600 \mathrm{mg}$ of clopidogrel was administered only if the patient had received no clopidogrel during the previous 7 days. All patients were discharged with a prescription for at least $75 \mathrm{mg}$ of acetylsalicylic acid indefinitely and for $75 \mathrm{mg}$ of clopidogrel for a minimum of 6 months after the index procedure.

At baseline, we evaluated all patients with a scoring system developed for the Synergy between PCI with Taxus and Cardiac Surgery (SYNTAX) study (ClinicalTrials.gov number, NCT00114972) to characterize the coronary vasculature regarding the number of lesions and their function, location, and complexity. ${ }^{10}$ The SYNTAX scale can range from 0 to 115 , with a higher score indicating more complex disease.

\section{FOLLOW-UP}

Patients were followed up by telephone or hospital visit at 1, 6, and 12 months and will continued to be followed annually for 5 years. At outpatient visits, patients were specifically questioned about the occurrence of angina or any adverse event.
Angiographic follow-up in 455 patients was planned at 13 months.

\section{QUANTITATIVE CORONARY ANGIOGRAPHY}

Findings on quantitative coronary angiography (QCA), which was performed with the use of the Cardiovascular Angiography Analysis System (CAAS) II (Pie Medical Imaging), were centrally assessed at one angiographic core laboratory (Cardialysis). ${ }^{11}$ QCA scans from patients returning for any repeat angiography within 14 days after the index procedure were not used in the follow-up QCA analysis, since the need for repeat revascularization in this period was not related to neointimal hyperplasia but rather to an acute response of the lesion to the procedure. These methods are consistent with those used in previous coronary stent trials, such as the Sirolimus Eluting Stent in de Novo Coronary Lesions (SIRIUS) trial (NCT00232765), and the Endeavor stent clinical trial program (Mauri L, Harvard Clinical Research Institute: personal communication). In addition, data from QCA analysis for patients returning for any repeat angiography later than 450 days (15 months) were also excluded from the statistical analysis, since they were outside the time limit for angiographic follow-up stipulated in the protocol. Additional methods and definitions with respect to QCA are provided in the Methods section in the Supplementary Appendix, available with the full text of this article at NEJM.org.

\section{PRIMARY AND SECONDARY END POINTS}

The primary end point was target-lesion failure, defined as a composite of death from cardiac causes, any myocardial infarction (not clearly attributable to a nontarget vessel), or clinically indicated target-lesion revascularization at 12 months. Secondary clinical end points were a composite of death from any cause, any myocardial infarction (Q-wave or non-Q-wave), or any revascularization (either a percutaneous or surgical procedure with either a clinical or nonclinical indication), as well as the individual components of the composite; definite, probable, possible, and overall stent thrombosis, defined according to the Academic Research Consortium definition ${ }^{12}$; and acute procedure, device, and lesion success. (Definitions of all study end points are provided in the Methods section in the Supplementary Appendix.) Quantitative angiographic end points included in-stent and in-segment percent stenosis, rate of binary 
restenosis, minimal lumen diameter, and late lumen loss.

\section{STATISTICAL ANALYSES}

This trial was powered for noninferiority testing of the primary end point at 12 months on an intention-to-treat basis. Full details of the samplesize calculation for the noninferiority primary and secondary end points are provided in the Methods section in the Supplementary Appendix.

Descriptive statistics for the secondary clinical end points are provided. Categorical variables are reported as counts and percentages, and between-group differences were assessed with the use of Fisher's exact test. Continuous variables are presented as means $\pm \mathrm{SD}$ and were compared with the use of a two-sample t-test. The Kaplan-Meier method was used to calculate the time to clinical end points, and the log-rank test was used to compare between-group differences. Unless otherwise specified, a two-sided $P$ value of less than 0.05 was considered to indicate statistical significance.

\section{RESULTS}

\section{PATIENTS}

A total of 2292 patients with 3366 lesions were randomly assigned to receive either zotarolimuseluting stents (1140 patients with 1661 lesions) or everolimus-eluting stents (1152 patients with 1705 lesions) (Fig. 1 in the Supplementary Appendix). A total of 21 patients $(1.8 \%)$ in the zotarolimus-stent group and $26(2.3 \%)$ in the everolimus-stent group were lost to follow-up or withdrew consent before the 12-month cutoff date, leaving 1119 patients in the zotarolimus-stent group and 1126 in the everolimus-stent group for inclusion in the intention-to-treat analysis.

Baseline clinical and angiographic characteristics were similar in the two study groups (Tables 1 and 2). Total stent lengths per patient and per lesion were significantly higher in the everolimus-stent group (Table 2). However, this factor had no detrimental effect on 12-month clinical outcomes (Table 3, and Table 1 in the Supplementary Appendix).

The primary end point of target-lesion failure - a composite of death from cardiac causes, any myocardial infarction, or target-lesion revascularization - occurred in 92 patients (8.2\%) in the zotarolimus-stent group and 94 patients $(8.3 \%)$ in the everolimus-stent group (Table 3 and Fig. 1A). We confirmed noninferiority of the zotarolimus-eluting stent, with an absolute risk difference of $-0.1 \%$ and the upper limit of the one-sided $95 \%$ confidence interval of $1.8 \%$ ( $\mathrm{P}<0.001$ in one-sided noninferiority analysis). The rates for the individual components of the primary end point were similar to those for the composite end point (Fig. 1B, 1C, and 1D). The findings for the primary end point were consistent across prespecified stratified analyses (Fig. 2 in the Supplementary Appendix).

Patients in the zotarolimus-stent group, as compared with the everolimus-stent group, had significantly reduced rates of death from any cause while they were hospitalized $(0.1 \%$ vs. $0.8 \%, \mathrm{P}=0.02)$ and at 30 days $(0.2 \%$ vs. $0.9 \%$, $\mathrm{P}=0.04$ ) because of a nonsignificant increased rate of death at 30 days in the everolimus-eluting stent group from both cardiac causes $(0.2 \%$ vs $0.7 \%, P=0.11)$ and noncardiac causes $(0 \%$ versus $0.2 \%, \mathrm{P}=0.50$ ). At 12 months, the between-group difference in the rate of death from any cause was no longer significant $(1.6 \%$ vs. $2.8 \%$, $\mathrm{P}=0.08$ ) (Table 3).

At 12 months, the rate of definite stent thrombosis was significantly higher in the zotarolimusstent group $(1.2 \%)$ than in the everolimus-stent group $(0.3 \%, \mathrm{P}=0.01)$, which was primarily related to a higher rate of definite stent thrombosis at 30 days in the zotarolimus-stent group $(0.8 \%)$ than in the everolimus-stent group $(0.1 \%$, $\mathrm{P}=0.01$ ). Rates of probable or possible stent thrombosis and of the composite of definite, probable, or possible stent thrombosis were similar in the two groups at all time points (Table 3, and Table 1 in the Supplementary Appendix). A temporal breakdown of all definite and probable episodes of stent thrombosis, along with the worst hierarchical outcome during a 12-month period, is shown in Figure 2 (for details, see the Results section and Table 2 in the Supplementary Appendix).

The secondary angiographic end point, the in-stent percent stenosis at 13 months, was determined at a median of 401 days (interquartile range, 394 to 420) in the zotarolimus-stent group and 409 days (interquartile range, 395 to 426 ) in the everolimus-stent group. The percent stenosis achieved the prespecified criterion for noninferiority, with $21.65 \pm 14.42 \%$ in the zotarolimusstent group versus $19.76 \pm 14.64 \%$ in the everolimus-stent group, a difference of $2.03 \%$ measured as a least-square mean with an upper limit of 


\begin{tabular}{|c|c|c|c|}
\hline Variable & $\begin{array}{l}\text { Zotarolimus-Eluting } \\
\text { Stent }(\mathrm{N}=1140)\end{array}$ & $\begin{array}{l}\text { Everolimus-Eluting } \\
\text { Stent }(\mathrm{N}=1152)\end{array}$ & $\begin{array}{l}\text { Difference } \\
(95 \% \mathrm{Cl}) \dagger\end{array}$ \\
\hline Age $-y r$ & $64.4 \pm 10.9$ & $64.2 \pm 10.8$ & $0.2(-0.7$ to 1.1$)$ \\
\hline Male sex - no. (\%) & $874(76.7)$ & $889(77.2)$ & -0.5 ( -4.0 to 2.9$)$ \\
\hline \multicolumn{4}{|l|}{ Coexisting condition — no. (\%) } \\
\hline Diabetes mellitus & $268(23.5)$ & $270(23.4)$ & $0.1(-3.4$ to 3.5$)$ \\
\hline Arterial hypertension & $810(71.1)$ & $821(71.3)$ & $-0.2(-3.9$ to 3.5$)$ \\
\hline Hyperlipidemia & $729(63.9)$ & $780(67.7)$ & $-3.8(-7.6$ to 0.1$)$ \\
\hline \multicolumn{4}{|l|}{ Cardiac risk factor } \\
\hline Current smoker — no. (\%) & $302(26.5)$ & $305(26.5)$ & $0.0(-3.6$ to 3.6$)$ \\
\hline $\begin{array}{l}\text { Premature coronary artery disease in first-degree } \\
\text { relative - no./total no. (\%) }\end{array}$ & $327 / 960(34.1)$ & $361 / 983(36.7)$ & $-2.7(-6.9$ to 1.6$)$ \\
\hline Previous myocardial infarction — no./total no. (\%) & $324 / 1122(28.9)$ & $341 / 1120(30.4)$ & $-1.6(-5.4$ to 2.2$)$ \\
\hline $\begin{array}{l}\text { Previous percutaneous coronary intervention - } \\
\text { no. (\%) }\end{array}$ & $363(31.8)$ & $370(32.1)$ & $-0.3(-4.1$ to 3.5$)$ \\
\hline Previous coronary-artery bypass grafting — no. (\%) & $114(10.0)$ & $110(9.5)$ & $0.5(-2.0$ to 2.9$)$ \\
\hline $\begin{array}{l}\text { Previous revascularization for angina or myo- } \\
\text { cardial infarction — no. (\%) }\end{array}$ & $996(87.4)$ & $1022(88.7)$ & $-1.3(-4.0$ to 1.3$)$ \\
\hline \multicolumn{4}{|l|}{ Clinical characteristic } \\
\hline Stable angina — no. (\%) & $382(33.5)$ & $416(36.1)$ & $-2.6(-6.5$ to 1.3$)$ \\
\hline Unstable angina - no. (\%) & $221(19.4)$ & $218(18.9)$ & $0.5(-2.8$ to 3.7$)$ \\
\hline Myocardial infarction — no. (\%) & $393(34.5)$ & $388(33.7)$ & $0.8(-3.1$ to 4.7$)$ \\
\hline $\begin{array}{l}\text { Left ventricular ejection fraction }<30 \%-\text { no./ } \\
\text { total no. (\%) }\end{array}$ & $17 / 610(2.8)$ & $13 / 608(2.1)$ & $0.7(-1.1$ to 2.4$)$ \\
\hline Multivessel disease — no. (\%) & $666(58.4)$ & $682(59.2)$ & $-0.8(-4.8$ to 3.2$)$ \\
\hline \multicolumn{4}{|l|}{ Target-vessel location — no. (\%) } \\
\hline Left main artery & $25(2.2)$ & $29(2.5)$ & $-0.3(-1.6$ to 0.9$)$ \\
\hline Left anterior descending artery & $600(52.6)$ & $560(48.6)$ & $4.0(-0.1$ to 8.1$)$ \\
\hline Left circumflex artery & $376(33.0)$ & $379(32.9)$ & $0.1(-3.8$ to 3.9$)$ \\
\hline Right coronary artery & $425(37.3)$ & $476(41.3)$ & $-4.0(-8.0$ to 0.0$)$ \\
\hline Bypass graft — no. (\%) & $28(2.5)$ & $28(2.4)$ & $0.0(-1.2$ to 1.3$)$ \\
\hline \multicolumn{4}{|l|}{ Complexity of coronary artery disease } \\
\hline No. of treated lesions per patient & $1.46 \pm 0.73$ & $1.48 \pm 0.77$ & $-0.02(-0.08$ to 0.04$)$ \\
\hline SYNTAX scoret & $14.8 \pm 9.3$ & $14.6 \pm 9.2$ & $0.2(-0.6$ to 1.0$)$ \\
\hline $\begin{array}{l}\text { At least one small vessel (reference vessel } \\
\text { diameter, } \leq 2.75 \mathrm{~mm})- \text { no./total no. (\%) }\end{array}$ & $652 / 962(67.8)$ & $656 / 973(67.4)$ & $0.4(-3.8$ to 4.5$)$ \\
\hline $\begin{array}{l}\text { At least one lesion length }>18 \mathrm{~mm}-\text { no./ } \\
\text { total no. (\%) }\end{array}$ & $175 / 962(18.2)$ & $206 / 973(21.2)$ & $-3.0(-6.5$ to 0.6$)$ \\
\hline $\begin{array}{l}\text { At least one bifurcation or trifurcation - no./ } \\
\text { total no. (\%) }\end{array}$ & $190 / 1126(16.9)$ & $202 / 1139(17.7)$ & $-0.9(-4.0$ to 2.3$)$ \\
\hline At least one total occlusion — no./total no. (\%) & $184 / 1127(16.3)$ & $197 / 1145(17.2)$ & $-0.9(-4.0$ to 2.2$)$ \\
\hline At least one in-stent restenosis — no./total no. (\%) & $91 / 1126(8.1)$ & $91 / 1139(8.0)$ & $0.1(-2.1$ to 2.3$)$ \\
\hline Off-label stent use - no. (\%)』 & $764(67.0)$ & $756(65.6)$ & $1.4(-2.5$ to 5.3$)$ \\
\hline
\end{tabular}

* Plus-minus values are means $\pm \mathrm{SD}$. $\mathrm{Cl}$ denotes confidence interval.

$\uparrow$ The value is the difference in the zotarolimus-stent group, as compared with the everolimus-stent group.

$T$ The SYNTAX score can range from 0 to 115, with higher scores indicating a greater complexity of disease.

$\int$ Off-label stent use included the placement of a stent in a patient with at least one of the following clinical or lesion characteristics: renal insufficiency (creatinine level, $\geq 140 \mu \mathrm{mol}$ per liter [1.6 mg per deciliter]), an ejection fraction of less than $30 \%$, the occurrence of acute myocardial infarction within the previous 72 hours, more than one lesion per vessel, at least two vessels with stents, a lesion measuring more than $27 \mathrm{~mm}$, bifurcation, bypass grafts, in-stent restenosis, unprotected left main artery, lesions with thrombus, or total occlusion. 


\begin{tabular}{|c|c|c|c|c|}
\hline & $\begin{array}{l}\text { Zotarolimus-Eluting } \\
\text { Stent }(\mathrm{N}=1140)\end{array}$ & $\begin{array}{l}\text { Everolimus-Eluting } \\
\text { Stent }(\mathrm{N}=1152)\end{array}$ & $\begin{array}{l}\text { Difference } \\
(95 \% \mathrm{Cl}) \grave{i}\end{array}$ & P Value \\
\hline \multicolumn{5}{|l|}{ Before index procedure } \\
\hline \multicolumn{5}{|l|}{ Lesion length $-\mathrm{mm}$} \\
\hline Mean & $11.89 \pm 7.50$ & $12.15 \pm 7.86$ & $0.26(-0.83$ to 0.32$)$ & \\
\hline Range & $0.1-73.3$ & $1.3-67.8$ & & \\
\hline Reference vessel diameter - $\mathrm{mm}$ & $2.63 \pm 0.57$ & $2.63 \pm 0.58$ & $0.00(-0.04$ to 0.05$)$ & \\
\hline Minimum lumen diameter $-\mathrm{mm}$ & $0.95 \pm 0.54$ & $0.93 \pm 0.52$ & $0.02(-0.02$ to 0.06$)$ & \\
\hline Percent stenosis — \% & $63.59 \pm 18.41$ & $64.18 \pm 18.19$ & $-0.58(-1.84$ to 0.67$)$ & \\
\hline Thrombus - no./total no. (\%) & $80 / 1518(5.3)$ & $75 / 1551(4.8)$ & $0.4(-1.1$ to 2.0$)$ & \\
\hline Moderate or heavy calcification - no./total no. (\%) & $351 / 1599(22.0)$ & $323 / 1634(19.8)$ & $2.2(-0.6$ to 5.0$)$ & \\
\hline TIMI score of 0 or $1-$ no./total no. (\%) & $249 / 1635(15.2)$ & $264 / 1672(15.8)$ & $-0.6(-3.0$ to 1.9$)$ & \\
\hline \multicolumn{5}{|l|}{ After index procedure } \\
\hline \multicolumn{5}{|l|}{ No. of stents } \\
\hline Per patient & $1.90 \pm 1.21$ & $2.02 \pm 1.34$ & $-0.12(-0.23$ to -0.02$)$ & 0.02 \\
\hline Per lesion & $1.15 \pm 0.42$ & $1.18 \pm 0.45$ & $-0.03(-0.06$ to -0.01$)$ & 0.02 \\
\hline \multicolumn{5}{|l|}{ Total stent length $-\mathrm{mm}$} \\
\hline Per patient & $34.42 \pm 24.49$ & $36.98 \pm 26.49$ & $-2.56(-4.65$ to -0.47$)$ & 0.02 \\
\hline Per lesion & $20.87 \pm 9.76$ & $21.68 \pm 10.16$ & $-0.81(-1.44$ to 0.18$)$ & 0.01 \\
\hline Balloon dilatation — no./total no. (\%) & $780 / 1122(69.5)$ & $799 / 1138(70.2)$ & $-0.7(-4.5$ to 3.1$)$ & 0.75 \\
\hline Received study stent only — no./total no. (\%) & $1117 / 1140(98.0)$ & $1116 / 1152(96.9)$ & $1.1(-0.2$ to 2.4$)$ & 0.11 \\
\hline \multicolumn{5}{|l|}{ Minimum lumen diameter $-\mathrm{mm}$} \\
\hline No. of lesions & 1638 & 1674 & & \\
\hline In-stent & $2.36 \pm 0.52$ & $2.38 \pm 0.53$ & $-0.01(-0.05$ to 0.02$)$ & 0.46 \\
\hline In-segment & $2.06 \pm 0.54$ & $2.06 \pm 0.55$ & $0.00(-0.04$ to 0.03$)$ & 0.89 \\
\hline \multicolumn{5}{|l|}{ Diameter stenosis — \% } \\
\hline In-stent & $14.59 \pm 10.59$ & $14.19 \pm 10.57$ & $0.40(-0.32$ to 1.12$)$ & 0.28 \\
\hline In-segment & $23.30 \pm 11.71$ & $22.99 \pm 11.65$ & $0.30(-0.49$ to 1.10$)$ & 0.46 \\
\hline \multicolumn{5}{|l|}{ Acute gain $-\mathrm{mm}$} \\
\hline No. of lesions & 1531 & 1557 & & \\
\hline In-stent & $1.42 \pm 0.58$ & $1.46 \pm 0.60$ & $-0.04(-0.08$ to 0.01$)$ & 0.10 \\
\hline In-segment & $1.11 \pm 0.59$ & $1.13 \pm 0.62$ & $-0.03(-0.07$ to 0.02$)$ & 0.22 \\
\hline \multicolumn{5}{|l|}{ Successful outcome - no./total no. (\%) } \\
\hline Lesion & $1869 / 1889$ (98.9) & $1946 / 1963$ (99.1) & $-0.2(-0.8$ to 0.4$)$ & 0.62 \\
\hline Device & $1820 / 1876(97.0)$ & $1888 / 1954$ (96.6) & $0.4(-0.7$ to 1.5$)$ & 0.52 \\
\hline Procedure & $1060 / 1121(94.6)$ & $1063 / 1128(94.2)$ & 0.3 (-1.6 to 2.2 ) & 0.79 \\
\hline
\end{tabular}

* Plus-minus values are means \pm SD. Cl denotes confidence interval, and TIMI Thrombolysis in Myocardial Infarction.

$\uparrow$ The value is the difference in the zotarolimus-stent group, as compared with the everolimus-stent group.

$\downarrow$ Definitions for lesion, device, and procedural success are provided in the Methods section in the Supplementary Appendix.

4.73 for the one-sided $95 \%$ confidence interval ( $\mathrm{P}=0.04$ for noninferiority). Of note, there was a significant difference in in-segment late loss in favor of the everolimus-eluting stent, with $0.15 \pm 0.43 \mathrm{~mm}$ in the zotarolimus-stent group versus $0.06 \pm 0.40 \mathrm{~mm}$ in the everolimus-stent group $(\mathrm{P}=0.04)$, whereas no significant betweengroup differences were observed for in-stent late loss $(0.27 \pm 0.43 \mathrm{~mm}$ vs. $0.19 \pm 0.40 \mathrm{~mm}, \mathrm{P}=0.08)$, in-segment binary restenosis $(5.2 \%$ vs. $6.5 \%$, 


\begin{tabular}{|c|c|c|c|c|}
\hline \multirow[t]{2}{*}{ Outcome } & $\begin{array}{l}\text { Zotarolimus-Eluting } \\
\text { Stent }(\mathrm{N}=1119)\end{array}$ & $\begin{array}{l}\text { Everolimus-Eluting } \\
\text { Stent }(\mathrm{N}=1126)\end{array}$ & $\begin{array}{l}\text { Difference } \\
(95 \% \mathrm{Cl}) 广 \overline{1}\end{array}$ & P Value \\
\hline & \multicolumn{2}{|c|}{ no. (\%) } & & \\
\hline Target-lesion failure & $92(8.2)$ & $94(8.3)$ & $-0.1(-2.4$ to 2.2$)$ & 0.94 \\
\hline \multicolumn{5}{|l|}{ Death } \\
\hline From any cause & $18(1.6)$ & $31(2.8)$ & $-1.1(-2.4$ to 0.1$)$ & 0.08 \\
\hline From cardiac cause & $15(1.3)$ & $19(1.7)$ & $-0.3(-1.4$ to 0.7$)$ & 0.61 \\
\hline \multicolumn{5}{|l|}{ Target-vessel myocardial infarction $\mathbb{S}$} \\
\hline Any & $47(4.2)$ & $46(4.1)$ & $0.1(-1.5$ to 1.8$)$ & 0.92 \\
\hline Q-wave & $8(0.7)$ & $5(0.4)$ & $0.3(-0.4$ to 0.9$)$ & 0.42 \\
\hline Non-Q-wave & $40(3.6)$ & $41(3.6)$ & $-0.1(-1.6$ to 1.5$)$ & 1.00 \\
\hline \multicolumn{5}{|l|}{ Clinically indicated target-lesion revascularization } \\
\hline Any & $44(3.9)$ & $38(3.4)$ & $0.6(-1.0$ to 2.1$)$ & 0.50 \\
\hline Coronary-artery bypass grafting & $6(0.5)$ & $8(0.7)$ & $-0.2(-0.8$ to 0.5$)$ & 0.79 \\
\hline Percutaneous coronary intervention & $38(3.4)$ & $31(2.8)$ & 0.6 ( -0.8 to 2.1$)$ & 0.39 \\
\hline Myocardial infarction & $151(13.5)$ & $153(13.6)$ & $-0.1(-2.9$ to 2.7$)$ & 0.95 \\
\hline \multicolumn{5}{|l|}{ Clinically indicated target-vessel revascularization } \\
\hline Any & $55(4.9)$ & $54(4.8)$ & $0.1(-1.7$ to 1.9$)$ & 0.92 \\
\hline Coronary-artery bypass grafting & $7(0.6)$ & $9(0.8)$ & $-0.2(-0.9$ to 0.5$)$ & 0.80 \\
\hline Percutaneous coronary intervention & $48(4.3)$ & $48(4.3)$ & 0.0 (-1.6 to 1.7$)$ & 1.00 \\
\hline $\begin{array}{l}\text { Death from cardiac causes or target-vessel myocardial } \\
\text { infarction } \mathbb{}\end{array}$ & $60(5.4)$ & $61(5.4)$ & -0.1 (-1.9 to 1.8$)$ & 1.00 \\
\hline Major adverse cardiac event $\|$ & $97(8.7)$ & $109(9.7)$ & $-1.0(-3.4$ to 1.4$)$ & 0.42 \\
\hline Target-vessel failure*** & $101(9.0)$ & $108(9.6)$ & $-0.6(-3.0$ to 1.8$)$ & 0.66 \\
\hline Patient-oriented composite end point & $163(14.6)$ & $164(14.6)$ & 0.0 (-2.9 to 2.9$)$ & 1.00 \\
\hline \multicolumn{5}{|l|}{ Definite stent thrombosis (0-360 days) } \\
\hline All patients & $13(1.2)$ & $3(0.3)$ & $0.9(0.2$ to 1.6$)$ & 0.01 \\
\hline Acute (0-1 day) & $4(0.4)$ & $1(0.1)$ & $0.3(-0.1$ to 0.7$)$ & 0.22 \\
\hline Subacute (2-30 days) & $5(0.4)+\iint 0$ & 0 & $0.4(0.1$ to 0.8$)$ & 0.03 \\
\hline Late (31-360 days) & $5(0.4)+$ & $2(0.2)$ & $0.3(-0.2$ to 0.7$)$ & 0.29 \\
\hline \multicolumn{5}{|l|}{ Probable stent thrombosis (0-360 days) } \\
\hline All patients ( $0-360$ days) & $6(0.5)$ & $5(0.4)$ & $0.1(-0.5$ to 0.7$)$ & 0.77 \\
\hline Acute $(0-1$ day) & $1(0.1) \iint$ & $1(0.1)$ & $0.0(-0.2$ to 0.2$)$ & 1.00 \\
\hline Subacute ( $2-30$ days) & $3(0.3)$ & $4(0.4)$ & $-0.1(-0.5$ to 0.4$)$ & 1.00 \\
\hline Late (31-360 days) & $2(0.2)$ & 0 & $0.2(-0.1$ to 0.4$)$ & 0.25 \\
\hline \multicolumn{5}{|l|}{ Stent thrombosis (0-360 days) } \\
\hline Possible & $9(0.8)$ & $9(0.8)$ & $0.0(-0.7$ to 0.7$)$ & 1.00 \\
\hline Definite or probable & $18(1.6)$ & $8(0.7)$ & 0.9 (0.0 to 1.8$)$ & 0.05 \\
\hline Definite, probable, or possible & $26(2.3)$ & $17(1.5)$ & $0.8(-0.3$ to 1.9$)$ & 0.17 \\
\hline
\end{tabular}

* This trial was powered for noninferiority testing of the primary end point at 12 months on an intention-to-treat basis.

$\dagger$ The value is the difference in the zotarolimus-stent group, as compared with the everolimus-stent group.

$\mp$ Target-lesion failure was defined as death from cardiac causes, any myocardial infarction (not clearly attributable to a nontarget vessel), or clinically indicated target-lesion revascularization.

$\int$ Myocardial infarction was determined on the basis of the extended historical definition. ${ }^{13}$

9 Myocardial infarction was determined on the basis of the Academic Research Consortium definition. ${ }^{12}$

|| Major adverse cardiac events included a composite of death, myocardial infarction (Q-wave and non-Q wave), emergent coronary-artery bypass surgery, or repeat clinically indicated target-lesion percutaneous or surgical revascularization.

$* *$ Target-vessel failure was defined as death from cardiac causes, any myocardial infarction (not clearly attributable to a nontarget vessel), or clinically indicated target-vessel revascularization.

$\dagger$ T The patient-oriented composite end point was death from any cause, any myocardial infarction (Q-wave and non-Q wave), or any revascularization.

One patient had a definite stent thrombosis on both day 4 and day 31.

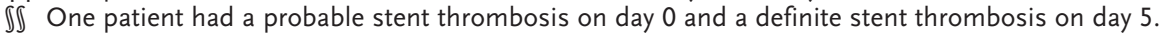




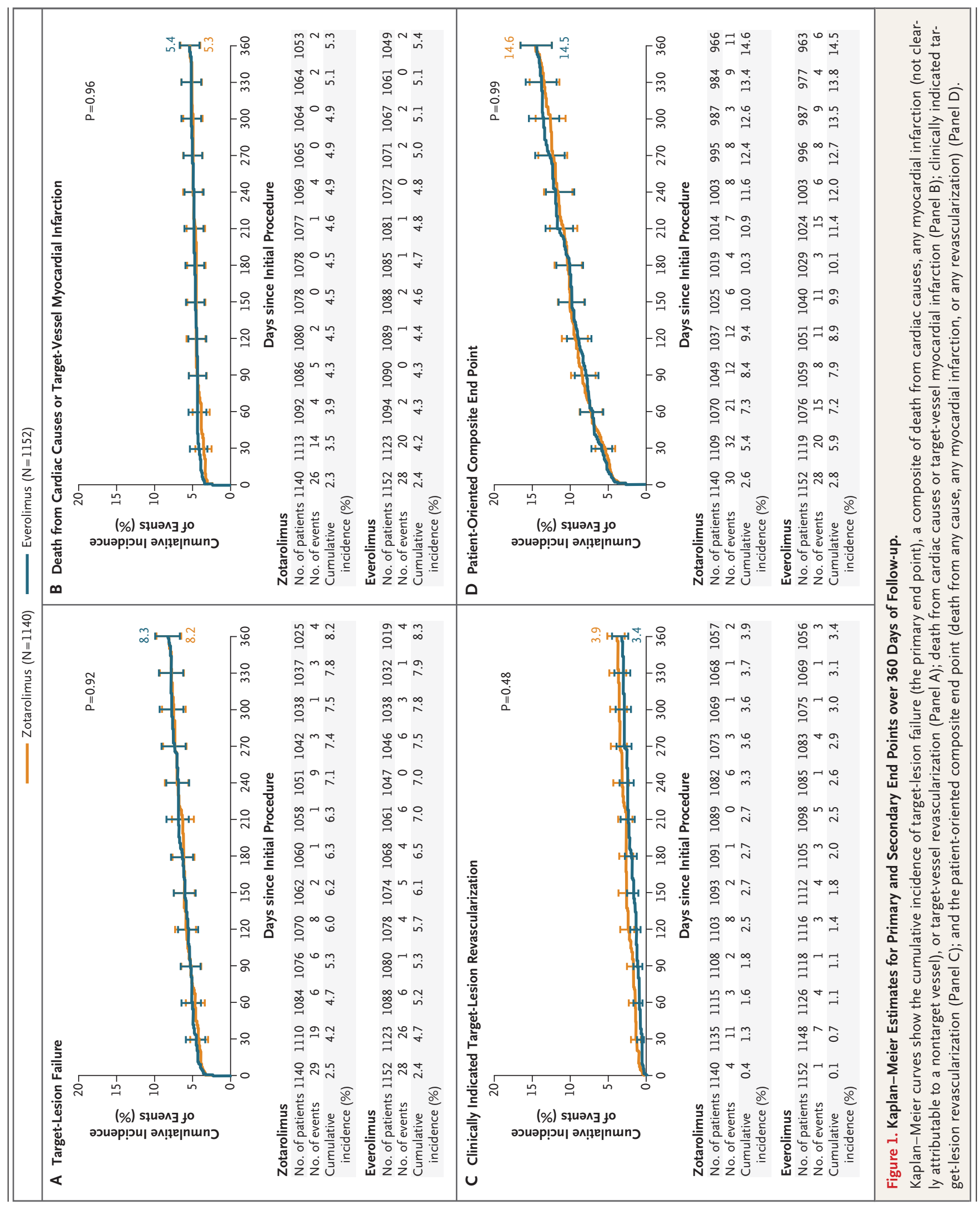




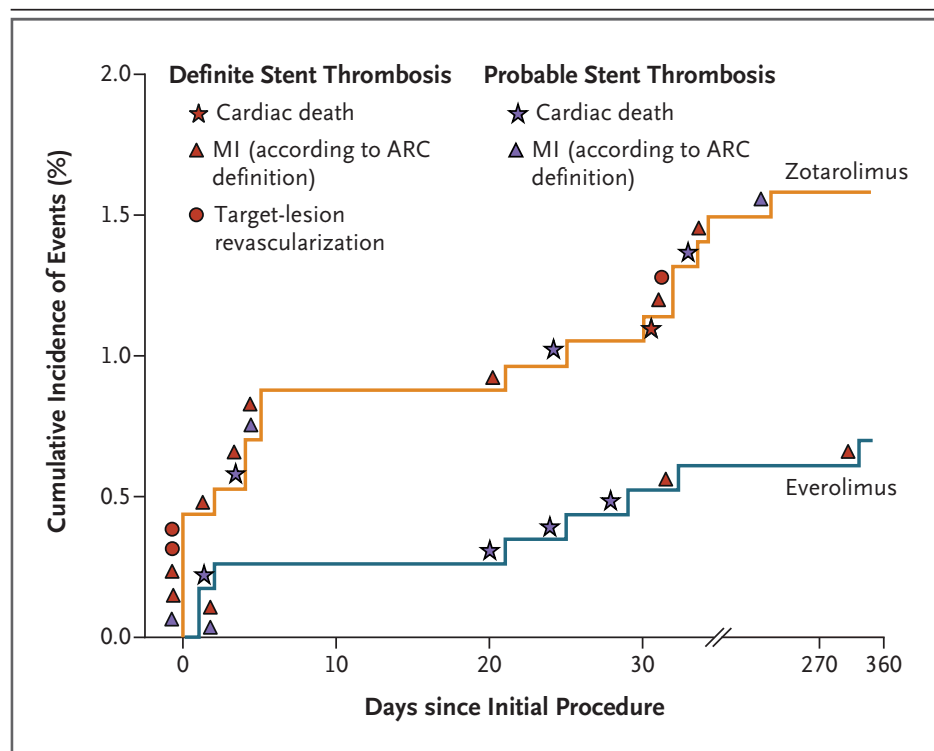

Figure 2. Cumulative Incidence of Definite or Probable Stent Thrombosis. Shown is the incidence of definite stent thrombosis (red) or probable stent thrombosis (blue) among 18 patients in the zotarolimus-stent group and 8 patients in the everolimus-stent group, along with the worst hierarchical clinical outcome, over 360 days of follow-up. ARC denotes Academic Research Consortium, and MI myocardial infarction.
$\mathrm{P}=0.67)$, or in-stent binary restenosis $(4.2 \%$ vs. $3.8 \%, P=1.00$ ) (Table 3 and Fig. 3 in the Supplementary Appendix). The primary and secondary end points that were calculated on a per-protocol basis are reported in the Results section in the Supplementary Appendix.

\section{DISCUSSION}

This study met the primary clinical end point by showing the noninferiority of the zotarolimuseluting stent, as compared with the everolimuseluting stent, when used in a population with minimal exclusion criteria. Historically, inclusion criteria for enrollment in randomized trials of coronary stents have included patients with "on-label" indications, including those with single de novo lesions of $27 \mathrm{~mm}$ or less in length in vessels with a reference diameter of 2.5 to $3.5 \mathrm{~mm}$. Among patients who were commonly excluded from such studies were those with coexisting illnesses, acute myocardial infarction, and multivessel disease.

In 2006, a Food and Drug Administration panel formally recognized the biohazard of late stent thrombosis, a phenomenon that was observed with increased frequency in the populations who had not been tested in previous ran- domized trials of coronary stents. The use and the risk of drug-eluting stents in patients in whom the placement of such stents was considered to be off-label for the device became a major concern. ${ }^{14,15}$ It was recommended that future trials should address a broad, unselected patient population, which would be more representative of everyday clinical practice. The lack of stringent exclusion criteria in our study resulted in the enrollment of a large proportion of patients with acute myocardial infarction, multivessel intervention, small-vessel disease, long lesions, or bifurcations or trifurcations - patients who represented those undergoing PCI in contemporary practice. Of note, results were consistent across all predefined subgroups.

In our study, we closely monitored the recruitment of patients, which showed that $44 \%$ of all patients undergoing PCI were enrolled in the trial. Therefore, we consider that our findings are highly generalizable to patients in everyday clinical practice.

Given the overall complexity of the patient population, the event rates were low and compared favorably with rates in previous "all-comer" studies, despite a somewhat higher mean SYNTAX score. ${ }^{16}$ Although the patient-oriented composite end point that was recommended by the Academic Research Consortium, ${ }^{13}$ which included all cardiovascular events, had an event rate of $14.6 \%$ in the two stent groups, this rate was lower than the rate of $18.3 \%$ reported in the angiographic group in the Fractional Flow Reserve Versus Angiography for Multivessel Evaluation (FAME) study (NCT00267774) in the context of a similar SYNTAX score. ${ }^{17}$

Using historical definitions of myocardial infarction, we compared rates in our trial with those in other all-comer trials. ${ }^{18-20}$ Before the start of the trial, it was decided that investigators should collect data on both creatine kinase and troponin levels, but the sponsor and the steering committee, in agreement with the data and safety monitoring board, decided to use the historical World Health Organization definitions of myocardial infarction, which were modified for an all-comer population. ${ }^{13}$ This decision was made to ensure that the trial results could be compared with historical coronary-stent studies. The measurement of troponin indeed resulted in a tripling of the rate of diagnosis of myocardial infarction. In the upcoming years, the increased sensitivity of the detection of troponin release will 
have to be carefully weighed against the reduced specificity for device-related coronary events.

Overall in our study, rates of stent thrombosis were low and similar to those in previous studies involving all comers or patients with acute coronary syndromes. ${ }^{18-22}$ Although we observed no significant between-group difference in overall rates of stent thrombosis, there were differences in rates of subacute definite events. We observed no significant between-group difference in the use of antiplatelet therapy, but there was a preponderance of stenting in the left anterior descending coronary artery and coexisting illnesses in patients with stent thrombosis. It is noteworthy that these episodes of stent thrombosis did not result in an excessive rate of myocardial infarction or death in the zotarolimus-stent group. Although our findings are hypothesisgenerating and require additional investigation, definitive conclusions will be obtained only from longer-term follow-up in large patient populations in studies that have sufficient statistical power to detect differences in rates of stent thrombosis.

In designing this trial, we wanted to subrandomize a population for angiographic follow-up, and in order to prevent revascularization that was not clinically indicated, we postponed angiographic follow-up for 4 weeks after the final clinical follow-up. This resulted in a decline in compliance for angiographic follow-up, since the majority of asymptomatic patients who were re- assured at the last clinic visit did not want to undergo repeat hospitalization for invasive angiography 4 weeks later. A similar observation was noted in the Harmonizing Outcomes with Revascularization and Stents in Acute Myocardial Infarction (HORIZONS-AMI) trial (NCT00433966). ${ }^{21}$ Despite this reduced compliance, the power of the angiographic follow-up study was maintained at more than $80 \%$ and can be interpreted with confidence. In view of the results of the in-stent and in-segment late loss, we concluded that there was no substantial difference between zotarolimus and everolimus in inhibitory effect on the neointima. Previously, the late loss observed with the zotarolimus stent was $0.12 \mathrm{~mm}$, $0.22 \mathrm{~mm}$, and $0.27 \mathrm{~mm}$ at 4,9 , and 13 months, respectively. ${ }^{5,6}$ Similarly, the previous late loss with the everolimus stent was $0.10 \mathrm{~mm}, 0.16 \mathrm{~mm}$, $0.19 \mathrm{~mm}$, and $0.34 \mathrm{~mm}$ at $6,8,13$, and 24 months, respectively. ${ }^{23-25}$ If there is a difference in inhibition of neointimal hyperplasia, it must be underscored that these values of late loss are far from clinically relevant, as confirmed by the low and similar rates of binary restenosis.

In conclusion, the new-generation zotarolimus-eluting stent was found to be as safe and effective as the everolimus-eluting stent in a group of patients for whom the procedure was considered to be predominantly off-label.

Supported by Medtronic CardioVascular.

Disclosure forms provided by the authors are available with the full text of this article at NEJM.org.

\section{REFERENCES}

1. Serruys PW, Kutryk MJB, Ong ATL. Coronary-artery stents. N Engl J Med 2006; 354:483-95.

2. Garg S, Serruys PW. Coronary stents - current status. J Am Coll Cardiol (in press).

3. Cook S, Ladich E, Nakazawa G, et al. Correlation of intravascular ultrasound findings with histopathological analysis of thrombus aspirates in patients with very late drug-eluting stent thrombosis. Circulation 2009;120:391-9.

4. Hezi-Yamit A, Sullivan C, Wong J, et al. Novel high-throughput polymer biocompatibility screening designed for SAR (structure-activity relationship): application for evaluating polymer coatings for cardiovascular drug-eluting stents. Comb Chem High Throughput Screen 2009;12: 664-76.

5. Meredith IT, Worthley S, Whitbourn $\mathrm{R}$, et al. The next-generation Endeavor Resolute stent: 4-month clinical and angiographic results from the Endeavor
Resolute first-in-man trial. EuroIntervention 2007;3:50-3.

6. Meredith IT, Worthley S, Whitbourn $\mathrm{R}$, et al. Clinical and angiographic results with the next-generation resolute stent system a prospective, multicenter, firstin-human trial. JACC Cardiovasc Interv 2009;2:977-85.

7. Meredith IT, Worthley S, Whitbourn $\mathrm{R}$, et al. Long-term clinical outcomes with the next generation Resolute Stent System: a report of the two-year follow-up from the RESOLUTE clinical trial. EuroIntervention 2010;5:692-7.

8. Udipi K, Chen M, Cheng P, et al. Development of a novel biocompatible polymer system for extended drug release in a next-generation drug-eluting stent. J Biomed Mater Res A 2008;85:1064-71.

9. Hezi-Yamit A, Sullivan C, Wong J, et al. Impact of polymer hydrophilicity on biocompatibility: implication for DES polymer design. J Biomed Mater Res A 2009;90:133-41.
10. Sianos G, Morel MA, Kappetein AP, et al. The SYNTAX Score: an angiographic tool grading the complexity of coronary artery disease. EuroIntervention 2005;1: 219-27.

11. Serruys PW, Foley D, De Feyter PJ, eds. Quantitative coronary angiography in clinical practice. Dordrecht, the Netherlands: Springer, 1994.

12. Cutlip DE, Windecker S, Mehran R, et al. Clinical end points in coronary stent trials: a case for standardized definitions. Circulation 2007;115:2344-51.

13. Vranckx P, Cutlip DE, Mehran R, et al. Myocardial infarction adjudication in contemporary all-comer stent trials: balancing sensitivity and specificity: addendum to the historical IM definitions used in stent studies. EuroIntervention 2010;5:871-4.

14. Farb A, Boam AB. Stent thrombosis redux - the FDA perspective. $\mathrm{N}$ Engl J Med 2007;356:984-7.

15. Serruys P. FDA panel, 7 and 8 December 2006 - the impact on our practice 
and research. EuroIntervention 2007;2: 405-7.

16. Wykrzykowska J, Garg S, Girasis C, et al. Value of SYNTAX score (SX) for risk assessment in all-comers population of the randomized LEADERS trial. J Am Coll Cardiol (in press).

17. Tonino PAL, De Bruyne B, Pijls NHJ, et al. Fractional flow reserve versus angiography for guiding percutaneous coronary intervention. N Engl J Med 2009;360: 213-24.

18. Windecker S, Remondino A, Eberli FR, et al. Sirolimus-eluting and paclitaxeleluting stents for coronary revascularization. N Engl J Med 2005;353:653-62.

19. Garg S, Sarno G, Serruys PW, et al. The twelve-month outcomes of a biolimus eluting stent with a biodegradable polymer compared with a sirolimus eluting stent with a durable polymer. EuroIntervention (in press).

20. Kedhi E, Joesoef KS, McFadden E, et al. Second-generation everolimus-eluting and paclitaxel-eluting stents in real-life practice (COMPARE): a randomised trial. Lancet 2010;375:201-9.

21. Stone GW, Lansky AJ, Pocock SJ, et al Paclitaxel-eluting stents versus bare-meta stents in acute myocardial infarction. N Engl J Med 2009;360:1946-59.

22. Wiviott SD, Braunwald E, McCabe $\mathrm{CH}$, et al. Intensive oral antiplatelet therapy for reduction of ischaemic events including stent thrombosis in patients with acute coronary syndromes treated with percutaneous coronary intervention and stenting in the TRITON-TIMI 38 trial: a subanalysis of a randomised trial. Lancet 2008;371:1353-63.
23. Serruys PW, Ruygrok P, Neuzner J, et al. A randomised comparison of an everolimus-eluting coronary stent with a paclitaxel-eluting coronary stent: the SPIRIT II trial. EuroIntervention 2006;2: 286-94.

24. Claessen BE, Beijk MA, Legrand V, et al. Two-year clinical, angiographic, and intravascular ultrasound follow-up of the XIENCE V everolimus-eluting stent in the treatment of patients with de novo native coronary artery lesions: the SPIRIT II trial. Circ Cardiovasc Interv 2009;2:339-47. 25. Stone GW, Midei M, Newman W, et al. Comparison of an everolimus-eluting stent and a paclitaxel-eluting stent in patients with coronary artery disease: a randomized trial. JAMA 2008;299:190313.

Copyright () 2010 Massachusetts Medical Society. 